\title{
Radiography for back pain presenting to accident and emergency departments
}

\author{
M. GIBSON \& N. ZOLTIE
}

Accident and Emergency Department, Leeds General Infirmary, Great George Street, Leeds.

\section{SUMMARY}

In order to determine the relevance of radiographs of the lumbar spine in an $A \& E$ department 225 consecutive patients presenting in a 6-month period with acute back pain were studied.

An analysis of the number of radiographs performed and their association with particular factors in the history and examination of the patient was performed. A total of 108 patients had radiographs $(48 \%)$, with a total of seven fractures $(6 \%$ of radiographs). All the patients with fractures had a history of direct trauma. Radiographs had no bearing on the decision to admit the patient.

The indications for radiography of the lumbar spine in the A\&E department are discussed.

\section{INTRODUCTION}

Back pain accounts for up to $1 \%$ of presentations to A\&E departments. The aetiology varies ranging from acute direct trauma, prolapsed intervertebral disc, musculoskeletal pain, or more rarely, tumour or infection.

The majority of problems do not need active intervention, but there is often difficulty in making a definitive diagnosis. This diagnosis depends on history, examination and further investigations, of which radiography is the most common. Radiographs of this area however are expensive and provide a large dose of radiation to a vulnerable part of the body (Cowen \& Taylor, 1986). For comparison, in our unit a standard chest radiograph subjects the patient to a measured $0.05 \mathrm{mGy}$, whereas an $A P$ lumbar spine necessitates $9.7 \mathrm{mGy}$ and a lateral lumbar spine radiographs results in $36.6 \mathrm{mGy}$ exposure (approximately 180 and 720 times the chest dose respectively).

Correspondence: $\mathrm{Mr}$ M Gibson, Accident and Emergency Department, Leeds General Infirmary, Great George St, Leeds LS1 3EX. 
The following study was performed in an attempt to provide guidelines for the use of radiography in the management of acute back pain presenting to an A\&E department.

\section{PATIENTS AND METHODS}

All patients between the ages of 16-65 who attended the A\&E Department complaining of pain in the lumbar region of less than $48 \mathrm{~h}$ duration over a 6-month period were entered into the study prospectively. A questionnaire was completed for each patient and the factors elicited were:

(a) a history of direct trauma, or spontaneous pain due to lifting, bending or twisting;

(b) the presence or absence of neurological signs and/or straight leg raising (SLR) of less than $40^{\circ}$;

(c) radiography performed; and

(d) outcome- admission, out patient appointment or discharged to the care of the GP

All patients who had radiographs had them reported by a Senior Radiologist as well as by the A\&E Doctor as this is the current practice in this department (Wardrope \& Chennels, 1985). A\&E records were scrutinized to check whether any patient had represented subsequently.

\section{RESULTS}

Questionnaires were completed for 225 patients. Eighty-two patients gave a history of trauma, and of these $56(68 \%)$ had radiographs with seven fractures detected (Table 1). A total of 143 patients had no history of trauma, $52(36 \%)$ having radiographs with no fractures detected.

Of the 17 patients with positive neurological signs including SLR of less than $40^{\circ}, 14$ had radiographs and two fractures were detected. Of the 208 patients with no neurological signs, $94(45 \%)$ had radiographs with 5 fractures detected.

These factors were then combined to give four groups - Group 1 (trauma with positive signs), Group 2 (trauma with no signs), Group 3 (no trauma with positive signs) and Group 4 (no trauma and no signs). The analysis of these groups is shown in Table 2.

Table 1. Results of questionnaire and radiography.

\begin{tabular}{lcc}
\hline & X-rayed & \# found \\
\hline Trauma $(n=82)$ & $56(68 \%)$ & 7 \\
No trauma $(n=143)$ & $52(36 \%)$ & 0 \\
\hline
\end{tabular}


Table 2. Analysis of groups.

\begin{tabular}{lcccc}
\hline & & & X-rayed & \# found \\
\hline & trauma & signs & & \\
Group 1 $(n=4)$ & + & + & 4 & 2 \\
Group 2 $(n=78)$ & + & - & 52 & 5 \\
Group 3 $(n=13)$ & - & + & 10 & 0 \\
Group 4 $(n=130)$ & - & - & 42 & 0 \\
\hline
\end{tabular}

Radiographs appeared to have no effect on the decision to admit patients, with four patients being admitted, two with and two without radiographs.

\section{DISCUSSION}

A recent report by the Royal College of Radiologists (National Radiation Protection Board, 1990) has highlighted yet again the need to reduce radiation for diagnostic purposes to the minimum acceptable for good practice. An internal audit of the use of spinal radiographs for acute back pain is thus timely and appropriate. This is especially so in view of the relatively large dose of radiation necessary to satisfactorily demonstrate this area.

The age range chosen for the study (16-65) includes the working population who are likely to have an accident or suffer from musculoskeletal or disc problems. For females, this includes the child-bearing age range when there is an even greater necessity to be cautious when requesting radiographic examinations. The upper limit was chosen in an attempt to avoid including degenerative disorders such as Paget's disease or osteoporosis and the lower limit to exclude disorders occuring in children or adolescents.

The decision to request radiographs was left to the clinical judgement of the A\&E Senior House Officers (SHOs). The reasons for requesting radiographs have been reported as to exclude bony abnormality,to reassure the patient or for medico-legal purposes (De Lacey et al., 1979). Junior doctors may also request more radiographs to compensate for lack of experience (Warren \& Ferguson, 1984). To compensate for this, accurate clinical guidelines from studies such as this may help.

All the patients who had a fracture on the radiograph had a history of direct trauma. None of the patients who presented following a lifting, twisting or bending strain had any significant abnormality seen on radiography. Therefore, doctors should rely more on clinical history and examination in their decisions about patient management (Waddell, 1982). It must be recognized, however, that for trauma in particular a negative result may be of as much value as a positive one (Wardrope \& Chennels, 1985) in terms of the disposal of the patient.

In view of the diagnostic yield, and the dose of radiation involved, we feel it would be ideal to restrict the number of radiographs performed to those patients 
who give a history of trauma with or without neurological signs. In our study this would have limited the number of patients to 56 with radiographs (as opposed to 108 ), resulting in a $50 \%$ reduction in the number of radiographs performed, with no significant abnormality being missed. We accept that the decision not to request radiographs in patients with positive neurological signs but no history of trauma is a difficult one. In our series of 13 such patients (group 3) 10 had radiographs. If the indications are expanded to include this group, this still reduces the number of radiographs to 66 out of 108 - a reduction of $42(38 \%)$.

We therefore conclude that more careful clinical attention to history and examination, combined with an awareness of the failure of any bony lesions to be found following radiography for non-trauma cases, can help reduce the numbers of requests for spinal radiography for acute back pain presenting to the $A \& E$ department. This will save time, money and over-exposure of patients to potentially damaging irradiation, particularly in the vulnerable age group examined in this study.

\section{ACKNOWLEDGEMENTS}

We would like to thank Mrs C. Rhodes and Mr J. McConnell for calculation of actual radiation doses measured in our unit.

\section{REFERENCES}

Cowen A. R. \& Taylor C. (1986) Patient absorbed doses in digital Greyscale fluorography. British Journal of Radiology 59, 689-693.

De Lacey G., Barker A., Wignall B., Reidy J. \& Harper J. (1979) Reasons for requesting radiographs in an accident and emergency department. British Medical Journal 283, 1595-1597.

National Radiation Protection Board. (1990) Patient dose reduction in diagnostic radiology. HMSO, London

Waddell G. (1982) An approach to backache. British Journal of Hospital Medicine 28, 187-219.

Wardrope J. \& Chennels P. M. (1985) Should all casualty X-rays be reviewed? British Medical Journal 290, 1638.

Warren R. A. \& Ferguson D. G. (1984) Why do accident and emergency doctors request X-rays? Archives of Emergency Medicine 3, 143-150. 